\title{
DISKONT ZA NEUTRŽIVOST AKCIJA: UTVREIVANJE I PRIMENA
}

\author{
Nina Milenković
}

KPMG d.o.o. Beograd, Beograd, Srbija

\begin{abstract}
Apstrakt:
Utvrđivanje diskonta za neutrživost akcija predstavlja jedan od zahtevnijih zadataka u proceni vrednosti kapitala, naročito kada su u pitanju manje kompanije koje posluju na slabije razvijenim tržištima. U radu su opisani različiti metodi utvrđivanja ovog diskonta u uslovima razvijenih tržišta, primena u zavisnosti od svrhe procene, kao i problemi sa kojima se susreće procenjivačka praksa u Srbiji i neka moguća rešenja.
\end{abstract}

Ključne reči:

diskont za neutrživost, zatvorene kompanije, nelikvidnost.
Korespondencija:

Nina Milenković

e-mail:

nmilenkovic@kpmg.com
UVOD

Većina metoda procene vrednosti kapitala koristi kao inpute i parametre tržišne podatke (komponente diskontne stope, tržišne multiplikatore, tržišne cene sredstava, i sl.). Time se implicitno podrazumeva da osnovni rezultat predstavlja utrživi kapital, tj. kapital koji je moguće u kratkom vremenu pretvoriti u gotovinu uz minimalne troškove; uobičajeno se koristi izraz "kao da je utrživ" (engl. as if marketable). Kada su u pitanju kompanije čije se akcije kotiraju na razvijenim berzama ovo uglavnom i jeste slučaj, ali kada su u pitanju kompanije čije se akcije kotiraju na slabo razvijenim berzama, privatne kompanije ili zatvorena društva, pretpostavka (pune) utrživosti uglavnom ne važi. Stoga je potrebno osnovni rezultat umanjiti za određeni diskont kako bi konačna procenjena vrednost kapitala odražavala činjenicu ograničene utrživosti.

U radu su ukratko opisani značenje i primena diskonta za neutrživost, kao i metodi za njegovo utvrđivanje, a zatim su izneta neka iskustva u proceni kapitala srpskih privrednih društava za različite svrhe.

Radi jednostavnosti, kada se govori o kapitalu kompanije koja je predmet procene, u radu je korišćen termin "akcije", bez obzira na pravnu formu kompanije, tj. da li je u pitanju akcionarsko društvo ili društvo sa ograničenom odgovornošću. Takođe, za većinu važnijih izraza navedeni su originalni izrazi na engleskom jeziku.

\section{DEFINICIJA, ZNAČENJE I PRIMENA}

Prema široko rasprostranjenoj definiciji iz Međunarodnog terminološkog rečnika pojmova vezanih za procenu vrednosti kapitala (International Glossary of Business Valuation Terms - IGBVT), koju koristi i Američko udruženja procenjivača (American Society of Appraisers, ASA), diskont za neutrživost (engl. discount for lack of marketability; u daljem tekstu: DLOM) predstavlja “iznos ili procenat za koji se umanjuje vrednost vlasničkog interesa da bi se odrazilo relativno odsustvo utrživosti” (ASA, 2009). 
Utrživost se definiše kao "mogućnost brze konverzije imovine u gotovinu uz minimalne troškove" (ASA, 2009). Često se uz ovu definiciju dodaje i da utrživost podrazumeva da se gotovina realizuje u roku od tri do pet radnih dana.

Iz definicije proizlazi i značenje - ako je umanjena mogućnost da se imovina konvertuje u gotovinu ili je potrebno više vremena da se gotovina realizuje, investitor će zahtevati nižu cenu i/ili više stope prinosa.

Iako su prilično slični, koncept utrživosti ne treba mešati sa konceptom likvidnosti. Likvidnost se u IGBVT i ASA (2009) definiše kao "mogućnost brze konverzije imovine u gotovinu ili isplate obaveze". U starijoj literaturi iz oblasti procene, ovi termini su često ravnopravno korišćeni, o čemu piše i Pratt (2009, str. 7), napominjući da se uglavnom utrživost više vezuje za mogućnost (pravo) konverzije, a likvidnost za njenu brzinu. U novijoj literaturi pravi se jasnija razlika između ova dva pojma. Primera radi, Finnerty (2013) navodi da se utrživost odnosi na pravnu ili ugovornu mogućnost vlasnika da imovinu proda ili na drugi način prenese vlasništvo, dok se likvidnost odnosi na relativnu jednostavnost konverzije imovine u gotovinu bez žrtvovanja dela njene suštinske vrednosti. U oba slučaja radi se o fleksibilnosti u pogledu promene vlasništva, ali iz drugačijih uglova. Kao što Finnerty i Park (2015) navode, neutrživost podrazumeva i nelikvidnost, dok obrnuta veza ne važi.

U proceni vrednosti kapitala (tačnije, vlasničkog interesa u kompaniji) problem neutrživosti (ili ograničene utrživosti) može se javiti u gotovo svim pravnim formama kompanija, ali je nezaobilazna kod privatnih, zatvorenih kompanija, te je najčešće potrebno primeniti diskont za neutrživost. Konkretna odluka da li će diskont biti primenjen zavisi od svrhe procene i definicije vrednosti, kao i od predmeta procene, tj. nivoa vrednosti koji se posmatra. Naime, ukoliko se radi o proceni fer tržišne vrednosti za potrebe potencijalne transakcije, tada je diskont obavezan, ali ukoliko se radi o proceni za potrebe statusne promene, DLOM ne mora da bude primenljiv.

Posebno interesantnu situaciju predstavlja procena fer vrednosti za potrebe isplate nesaglasnih akcionara $\mathrm{u}$ američkoj praksi. Naime, propisima je regulisano da, u cilju zaštite prava manjinskih akcionara, fer vrednost predstavlja proporcionalno (pro rata) učešće $u$ vrednosti kompanije, $t j$. da u slučajevima njihove nesaglasnosti ne treba primenjivati diskonte koji bi uobičajeno proizašli iz činjenice da je u pitanju manjinski paket. Međutim, u sudskoj praksi države New York u poslednje vreme više puta su donete odluke koje su podrazumevale primenu diskonta za neutrživost na manjinski paket akcija. Procenjivačka javnost već je bila podeljena po pitanju nivoa vrednosti na koji se primenjuje DLOM (nivo entiteta, tj. ukupnog kapitala ili nivo pojedinačnih vlasnika), a ove odluke dovele su do burne diskusije i sve češćih zahteva za objedinjenim stavom profesije po ovom pitanju (Mahler, 2011, 2016; Queckenbush, 2016).

\section{METODI UTVRĐIVANJA}

Kao i kod većine parametara koji se koriste u proceni, a koje nije moguće eksplicitno empirijski izmeriti ili utvrditi, ne postoji jedinstvena ili opšteprihvaćena metodologija utvrđivanja DLOM. Procenjivačima su na raspolaganju izvori i alati koji se mogu svrstati u nekoliko grupa:

- Empirijski modeli,

- Teorijski modeli,

- Specijalizovani softveri,

- Drugi izvori, kao što su akademske studije i sudska praksa u SAD.

\section{Empirijski modeli}

Empirijski modeli bazirani su na podacima o izvršenim transakcijama čiji su predmet bile akcije umanjene utrživosti. Postoje tri vrste empirijskih modela: studije vezane za akcije sa ograničenjima na trgovanje (restricted stock studies), studije o transakcijama pre inicijalne javne ponude (pre-IPO studies) i model troškova puštanja u opticaj (flotation cost model).

Studije vezane za akcije sa ograničenjima na trgovanje istorijski su bile najčešće korišćen izvor podataka za utvrđivanje DLOM. Pod akcijama i uopšteno hartijama od vrednosti sa ograničenjima podrazumevaju se hartije koje su po svim obeležjima identične običnim akcijama kojima se slobodno trguje, osim što za njih postoji zabrana trgovanja na otvorenim tržištima u određenom vremenskom periodu, pa se transfer vlasništva odvija putem poklona, nasleđa, privatnih transakcija, kompanijskih bonusa i sl. Studije koje analiziraju ove akcije imaju za cilj da utvrde razlike u cenama između ovih akcija i njihovih pandana kojima se slobodno trguje, a utvrđena razlika koristi se kao aproksimacija DLOM.

Osnovni nedostaci u korišćenju studija o akcijama sa ograničenjima su sledeći:

- analizirane akcije razlikuju se od akcija zatvorenih (privatnih) kompanija u više važnih aspekata, od kojih su neki: poznata dužina perioda bez trgovanja, transparentnost u finansijskom izveštavanju, likvidnost tržišta na kome stransakcije izvršavaju, i sl.

- diskonti utvrđeni u ovim studijama uglavnom imaju veoma širok raspon vrednosti,

- mnoge studije ne objavljuju detaljne informacije o obuhvaćenim transakcijama,

- veliki broj ovih studija je stariji od 30 godina.

Studije o transakcijama pre inicijalne javne ponude porede cene akcija kompanije postignute u privatnim transakcijama pre otvaranja kompanije za javnost sa tržišnom cenom akcija iste kompanije postignutom nakon inicijalne javne ponude.

Problemi u primeni pre-IPO studija su sledeći:

- transakcije pre otvaranja kompanije za javnost većinom se odvijaju sa insajderima, često u formi kompenzacije, što otežava prikupljanje podataka o cenama, 
- cene postignute u privatnim transakcijama u ovim studijama nisu korigovane za vremensku vrednost novca; iako se može uočiti da su diskonti niži što je transakcija bliže inicijalnoj javnoj ponudi, ne postoji zvanično objavljena analiza ove veze.

Model troškova puštanja u opticaj ocenjuje DLOM merenjem troškova "kreiranja utrživosti", tj. troškova inicijalne javne ponude u odnosu na ukupan priliv od IPO. Osnovni nedostatak ovog modela leži u činjenici da su kompanije koje izlaze na tržište uglavnom značajno veće od većine zatvorenih kompanija koje su predmet procene, te da su samim tim diskonti potcenjeni.

\section{Teorijski modeli}

Teorijski modeli koji se najčešće koriste su modeli koji koriste vrednovanje opcija (option pricing models), dugoročne opcije (long-term equity anticipation securities), model diskontovanog novčanog toka i model baziran na stopama prinosa.

Modeli za utvrđivanje DLOM preko vrednovanja opcija baziraju se na put opcijama na akcije privatne kompanije, sa idejom da je put opcija po prirodi slična akciji privatne kompanije: vlasnik ima pravo, ali ne i obavezu, da proda imovinu po utvrđenoj ceni na utvrđeni datum. U zavisnosti od modela, DLOM se određuje kao vrednost definisane put opcije ili razlika između vrednosti put opcije i cene akcije kompanije koja se procenjuje. Chaffee model zasniva se na evropskoj put opciji i njenom vrednovanju pomoću Black-Sholes modela, Longstaff model daje gornju granicu za DLOM, uz pretpostavku da vlasnik ima savršenu mogućnost izbora pravog trenutka za transakciju, dok Finnerty model koristi put opciju sa prosečnom izvršnom (strike) cenom (izračunatom kao prosek spot cena u određenom periodu).

Nedostaci ovih modela leže u njihovom glavnom alatu, tj. u subjektivnosti pretpostavki potrebnih za vrednovanje opcije, pre svega volatilnosti akcija, kao i investitorove mogućnosti izbora trenutka transakcije.

Model koji koristi dugoročne opcije u osnovi ima činjenicu da ove opcije imaju duži rok dospeća i predstavljaju trošak osiguranja od pada cene akcije u osnovi opcije. Trošak osiguranja računa se kao odnos između cene put opcije i njene izvršne cene i predstavlja minimalni zahtevani DLOM.

Osnovni nedostaci ovog modela su u tome što se dugoročne opcije teško nalaze na tržištu, a kompanije koje ih izdaju uglavnom su značajno veće od privatnih kompanija koje su predmet procene.

Model diskontovanog novčanog toka primenjuje se tako što se razvijaju dva skupa pretpostavki i dobijaju dva rezultata, jedan koji predstavlja utrživi paket i drugi koji predstavlja neutrživi paket, tako da njihov odnos predstavlja DLOM. Najpoznatiji među ovim modelima je Kvantitativni model diskonta za neutrživost (QMDM - Quantitative Marketability Disco- unt Model) Kristofera Mesera, jednog od vodećih svetskih teoretičara i praktičara u oblasti procene vrednosti kapitala.

Kritike ovog modela većinom se odnose na veliki broj pretpostavki, od kojih je najteže odrediv period držanja akcija u posedu. Osim toga, QMDM je često kritikovan kao "crna kutija", jer korisnik nema uvid u sam obračun.

Model baziran na stopama prinosa polazi od činjenice da investitori zahtevaju više stope prinosa ukoliko je akcija slabije utrživa. Na osnovu novčanih tokova (ostvarenih ili projektovanih) i empirijski utvrđenih odnosa stopa prinosa dolazi se do zahtevanog prinosa na neutržive akcije, a odatle i do impliciranog DLOM. Ovaj model je donekle hibridan, jer kao izvor za odnose stopa prinosa koristi empirijske studije (između ostalih, studije o akcijama sa ograničenjima na trgovanje).

Kritike ovog modela odnose se upravo na korišćenje prosečnih vrednosti iz empirijskih studija i diskutabilnoj uporedivosti između kompanija koje su poslužile za izračunavanje proseka i kompanije koja se procenjuje.

\section{Specijalizovani softveri}

Postoje brojni softveri za utvrđivanje DLOM, bazirani na različitim metodologijama, u zavisnosti od toga da li je kreator firma koja se pretežno bavi statističko-metodološkim istraživanjima ili procenjivačkom praksom. Dva primera koja su bila interesantna autoru ovog rada su softver koji je razvila firma FMV Opinions, Inc. koja se bavi istraživanjem i objavljivanjem studija o akcijama sa ograničenjima na trgovanje i DLOM "kalkulator" razvijen od strane konsultantske firme Vianello Forensic Consulting.

FMV softver, sudeći po metodološkom vodiču (5), nastao je kao sastavni deo softvera za korišćenje baze podataka o transakcijama akcija sa ograničenjima na trgovanje i obračun se bazira na toj vrsti podataka, ali uključuje detaljnu analizu kompanije koja se procenjuje (potrebno je uneti podatke iz finansijskih izveštaja) i selekciju transakcija koje će biti uključene u obračun na osnovu zadatih kriterijuma.

VFC kalkulator koristi Longstaff model i u metodološkom materijalu (6) izneti su argumenti u korist ovog modela i protivargumenti na uobičajene kritike. U sklopu samog kalkulatora, korisniku je ponuđen i raspored verovatnoća za dužinu perioda prodaje akcija (marketing period) i volatilnosti akcija, ali je moguće i ručno unošenje ovih parametara, pa rezultat može da bude baziran na jednom parametru određenom probabilistički a drugom deterministički, a moguće je i oba parametra odrediti probabilistički.

\section{Ostali izvori}

Akademske studije bile su popularan izvor podataka u ranijem periodu, ali se, s obzirom na činjenicu da su objavljene 
u periodu 1989-2002, danas ne bi mogle smatrati relevantnim niti aktuelnim izvorom informacija.

Sudske presude su relativno često korišćen izvor među američkim procenjivačima (pojedincima i manjim firmama), što nije neobično jer su sporovi u kojima se koriste procene vrednosti veoma česti, a sudska praksa u toj oblasti razvijena. Međutim, vodeći specijalisti ne preporučuju ovaj izvor, jer sudske odluke nisu uvek zasnovane na procenjivačkim principima; naprotiv, dešava se i da ih grubo prekrše.

\section{Noviji modeli}

Procenjivačka profesija kontinuirano radi na razvoju modela za utvrđivanje DLOM i u relevantnoj literaturi se često pojavljuju novi ili inovirani predlozi, kao što su korišćenje varijabilnih pretplatnih forvarda (predloženo od Fishman-a i Barenbaum-a, a kritikovano od strane Finnerty-ja i Park-a, 2015), uvođenje različitih distribucija verovatnoća u modele zasnovane na vrednovanju put opcija (Finnerty, 2013), izračunavanje inkrementalnih DLOM za akcije u okviru portfolija akcija (Grant, 2014) itd.

\section{IZAZOVI I ISKUSTVA IZ PROCENJIVAČKE PRAKSE U SRBIJI}

Procenjivačka praksa u Srbiji postoji nešto više od 25 godina, ali je i dalje u nekim segmentima nedovoljno razvijena, naročito kada se radi o proceni vrednosti kapitala. Profesija nije institucionalizovana, ne postoje lokalni standardi niti zakonska obaveza primene (bilo kojih) međunarodnih standarda, relativno mali broj pojedinaca poseduje potreban nivo poznavanja specifične metodologije, relativno mali broj klijenata i korisnika procene je dovoljno upućen u metodologiju i značenje rezultata itd. (razmatranje svih problema daleko prevazilazi okvire ovog rada). Deo problema je i posledica činjenice da je domaće tržište, kao i tržište drugih zemalja u užem regionu, prilično malo i da obim tražnje za uslugama procene kapitala sa stanovišta pojedinaca uglavnom ne može da opravda visoka ulaganja u specifično obrazovanje i troškove pristupa specifičnim izvorima podataka i procenjivačkim alatima.

S druge strane, neutrživost je karakteristika velikog broja kompanija u Srbiji i širem regionu. Iako berze formalno postoje, obim trgovanja je mali, a veoma malim brojem akcija se trguje kontinualno. U skladu s tim, diskont za neutrživost, teorijski gledano, trebalo bi da bude često primenjivan u procenama vrednosti kapitala.

Iz gore pomenutih razloga, izvori informacija za utvrđivanje DLOM za procenjivače u Srbiji uglavnom su nedostupni, često tehnički, a još češće finansijski (ukoliko nisu zaposleni u međunarodnim firmama koje pristup izvorima obezbeđuju kroz globalnu ili regionalnu mrežu). Zato procenjivači kapitala u Srbiji uglavnom koriste javno dostupne izvore (pretežno internet), a potom prikupljene podatke, u zavisnosti od znanja i iskustva, koriguju radi prilagođavanja konkretnim uslovima i faktorima.

Jedan od primera iz iskustva ovog autora jesu procene vrednosti kapitala društvenih preduzeća za potrebe prvih tenderskih privatizacija. Kako su bila u pitanju društvena preduzeća, tj. zatvoreni tip vlasništva, upotreba diskonta nametala se kao obavezna. S druge strane, izbor vida privatizacije implicirao je postojanje tražnje (potencijalnih kupaca), te je ocenjeno da diskont treba da bude na ispodprosečnom nivou (5-10\%). Kako su kasnija dešavanja pokazala, za neka preduzeća ova pretpostavka je bila potpuno pogrešna.

U današnjoj praksi odluka o primeni DLOM uglavnom se bazira na svrsi procene. Ukoliko se radi o proceni udela strane kompanije u kapitalu domaće radi finansijskog izveštavanja, ili utvrđivanju vrednosti radi potencijalne transakcije, diskont se uglavnom koristi i klijenti ga prihvataju u potpunosti (često i insistiraju na primeni). U slučajevima procene vrednosti akcija za potrebe statusne promene spajanja ili spajanja pripajanjem, diskont se najčešće ne primenjuje jer nije opravdan (izuzetak su pojedini slučajevi određivanja odnosa razmene akcija ako se akcijama jedne od kompanija koje učestvuju u transakciji trguje a akcijama ili udelima druge ne).

Najzad, specifičan slučaj predstavljaju procene vrednosti kapitala u slučajevima kada postoji mogućnost nesaglasnih akcionara, gde se pragmatično-intuitivni stav da je poželjno izbeći umanjenje vrednosti i smanjiti verovatnoću tužbe uobičajeno obrazlaže već pomenutim američkim propisima i pretežnom sudskom praksom.

\section{ZAKLJUČAK}

Neutrživost je uobičajena karakteristika vlasničkog interesa u privatnim kompanijama, te je u formiranju konačnog zaključka o procenjenoj vrednosti potrebno primeniti odgovarajući diskont. Većina procenjivača koristi jedan model ili studiju, ali moderni trendovi u proceni (a sve češće i procenjivački standardi) zahtevaju razmatranje i diskusiju više modela.

U radu je dat pregled modela i izvora informacija koji se koriste u razvijenim procenjivačkim praksama, uz konstataciju da je većina ovih izvora za procenjivače u Srbiji ograničeno dostupna. $S$ jedne strane, ovo procenjivače u Srbiji čini donekle hendikepiranim u pogledu postizanja visokog kvaliteta procene. $S$ druge strane, zbog prirode tržišta, klijenata i razloga za procenu (svrha procene), diskont za neutrživost još uvek nije široko primenljiv.

Sa razvojem tržišta i profesije biće potrebno poboljšanje situacije i obezbeđenje lokalnih izvora podataka, tj. podaka o diskontima specifičnim za uži region. U tom smislu, prikupljanje podataka o transakcijama i sprovođenje istraživanja analognog studijama o akcijama sa ograničenjima i pre-IPO studijama bilo bi veoma interesantno i korisno u budućnosti. 


\section{LITERATURA}

American Society of Appraisers. (2009). ASA Business Valuation Standards. Preuzeto 15. juna 2016. sa https://www.appraisers.org/docs/default-source/discipline_bv/bv-standards. pdf?sfvrsn $=0$

Finnerty, J.D. (2013). Using Put Option-based DLOM Models to Estimate Discounts for Lack of Marketability. Business Valuation Review, 31-32(4), 165-170. doi:10.5791/13-00001.1

Finnerty, J.D., \& Park, R.W. (2015). Collars, Prepaid Forwards, and the DLOM: Volatility Is the Missing Link. Business Valuation Review, 34(1), 24-30

Grant, D. (2014). Thoughts on Calculating DLOMs. Business Valuation Review, 33(4), 102-112.

Hitchner, J. R. (2011). Financial valuation: Applications and models. Determining Discounts for Lack of Marketability: A Companion Guide to The FMV Restricted Stock Study. doi:10.1002/9781119205517.oth9
Mahler, P. (2011). The Marketability Discount in Fair Value Proceedings: An Emperor Without Clothes? Preuzeto 11. septembra 2016. sa http://www.nybusinessdivorce.com/2011/07/ articles/valuation-discounts/the-marketability-discount-infair-value-proceedings-an-emperor-without-clothes/

Mahler, P. (2016). The DLOM Debate Heats Up. Preuzeto 11. septembra 2016. sa http://www.nybusinessdivorce.com/2016/01/ articles/valuation/the-dlom-debate-heats-up/

Pratt, S.P. (2009). Business valuation discounts and premiums. Hoboken: John Wiley \& Sons.

Quackenbush, W.C. (2016). DLOMs in N.Y. Statutory Fair Value Cases: A Follow-Up to Matthews. Preuzeto 11. septembra 2016. sa https://www.bvresources.com/products/businessvaluation-update

Vianello Forensic Consulting. (2014). Calculating ProbabilityBased Discounts for Lack of Marketability., Preuzeto 15. jula 2016. sa https://dlomcalculator.com/methodology/

\section{DISCOUNT FOR LACK OF MARKETABILITY: DETERMINING AND APPLICATION}

\section{Abstract:}

The determining of the discount for lack of marketability represents one of more demanding tasks in the capital value assessment, especially when it comes to smaller enterprises which operate in less developed markets. The paper describes various methods of determining this discount under the conditions of developed markets, its application depending on the purpose of assessment, as well as the problems the assessment practices encounter in Serbia, and some possible solutions.

\section{Keywords:}

discount for lack of marketability, closed companies,

(in)solvency 